The National Center for Family \& Marriage Research

@ Bowling Green State University

Family Profile No. 11, 2021

\title{
Median Age at First Marriage for Same-Sex and Different-Sex Couples, 2019
}

Authors: Krista K. Payne and Wendy D. Manning

Tracking of the age at first marriage has traditionally focused on all marriages, not considering the gender composition of the couple. After the legalization of marriage for all couples in the U.S. occurred in 2015, the U.S. Census Bureau changed their data collection to directly query respondents about same-sex and different-sex partnerships (see Manning and Payne, 2021). This profile uses data from the 2019 American Community Survey (ACS), 1-year estimates to determine men's and women's median ages at first marriage who are in different-sex and same-sex marriages. The ACS is ideal because it provides the best annual data on marriages in the last year and a large sample size allowing for direct estimation of the median age at first marriage (Simmons \& Dye, 2004). Based on the ACS, there were about 50,000 same-sex first marriages and 1.2 million different-sex first marriages in 2019.

Figure 1. Age at First Marriage by Gender and Couple Type Among Householders \& Spouses of Householders, 2019

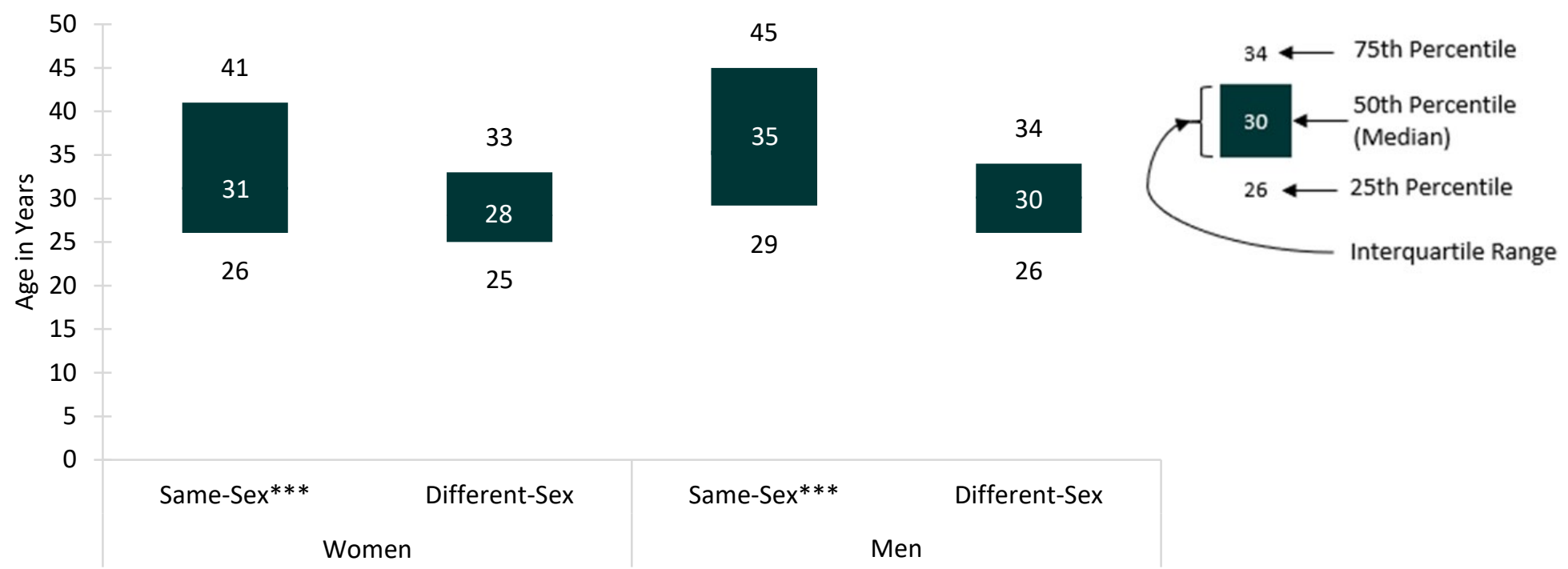

Source: NCFMR analysis of U.S. Census Bureau, American Community Survey 1-year estimates, 2019

Note: We use the term sex rather than gender because the U.S. Census Bureau asks about sex of the respondent and their spouse/husband/wife.

The figure presents the median age at first marriage. To capture the variability in the range of ages, we present the quartiles of age at first marriage with the lower bound representing the 25th percentile and the upper bound the 75th percentile. Significance of differences across groups are tested using Pearson chi-square tests.

- Among women in same-sex marriages, the median age at first marriage was 31. Among women in different-sex marriages it was significantly lower at 28 .

- The range in the age at first marriage was wider for women in same-sex marriages at 15 years (ranging from ages 26 to 41 ) than among women in different-sex marriages at 8 years (ranging from ages 25 to 33).

- The median age at first marriage among men entering a same-sex marriage (age 35) was significantly older than men entering a different-sex marriage (age 30).

- Similar to women, the age range of first marriage was broader among men entering a same-sex marriage at 16 years (ranging from 29 to 45) than among men entering a different-sex marriage at 8 years (ranging from 26 to 34 ).

- Traditionally, men's age at first marriage is about two years older than women's age at first marriage (FP-21-12). A gender gap in the age at marriage existed among same-sex couples and was twice as great (4 years) as the gap observed among different-sex couples. Men in same-sex marriages married at older ages than women in same-sex relationships, 35 years of age versus 28 . 


\section{Data Source:}

U.S. Census Bureau, American Community Survey, 1-year Estimates, Public Use Microdata Sample, 2019

\section{References:}

Payne, K. K. (2021). Median age at first marriage in the U.S., 2019. Family Profiles, FP-21-12. Bowling Green, OH: National Center for Family \& Marriage Research. https://doi.org/10.25035/ncfmr/fp-19-12.

Manning, W. D. \& Payne, K. K. (2021). Measuring marriage and cohabitation: Assessing same-sex relationship status in the current population survey. Demography.

Simmons, T., \& Dye, J. L. (2004, August). What has happened to median age at first marriage data? Paper presented at the Annual Meeting of the American Sociological Association, San Francisco.

\section{Suggested Citation:}

Payne, K. K. \& Manning, W. D. (2021). Median age at first marriage for same-sex and different-sex couples, 2019. Family Profiles, FP-21-11. Bowling Green, OH: National Center for Family \& Marriage Research. https://doi.org/10.25035/ncfmr/fp-21-11.

\section{\begin{tabular}{l|l} 
BCSU. & National Center for \\
Family \& Marriage Research
\end{tabular}}

http://www.bgsu.edu/ncfmr

ncfmr@bgsu.edu

(419) 372-3119

This project is supported with assistance from Bowling Green State University. From 2007 to 2013, support was also provided by the U.S. Department of Health and Human Services, Office of the Assistant Secretary for Planning and Evaluation. The opinions and conclusions expressed herein are solely those of the author(s) and should not be construed as representing the opinions or policy of any agency of the state or federal government. 